\title{
0 tempo da costura: afetos, subversão e intimidade em Call the midwife
} Time for sewing: affects, subversion and intimacy in Call the midwife

Karina Gomes Barbosa ${ }^{1}$

\footnotetext{
Professora do curso de Jornalismo e do Programa de Pós-Graduação em Comunicação e Temporalidades da Universidade Federal de Ouro Preto (Ufop).
} 
Resumo: este artigo analisa uma sequência do seriado britânico Call the midwife por meio da análise fílmica, sob o aporte dos estudos feministas e dos estudos culturais. Debruçamo-nos sobre o labor em torno da costura feminina realizada no confinamento do lar, em que se cose uma colcha, para discutir afetos, silêncios, tempo, intimidade e subversão. A série tem como tema central a maternidade e aborda o trabalho de um grupo de parteiras em uma região pobre da Inglaterra no fim dos anos 1950. Ao mesmo tempo que promove rupturas em relação a representações hegemônicas da casa e da costura, se alinha a visões contemporâneas mitificadoras da maternidade e do "ser mãe".

Palavras-chave: seriado; afetos; mulheres; feminismo; intimidade.

Abstract: this article analyzes a scene from the British series Call the midwife, using film analysis and the contribution of feminist studies. We studied the labor surrounding the feminine sewing made in the home confinement, especially the scene in which women sew a quilt to discuss affects, silences, time, intimacy and subversion. The central theme of this series is maternity and approaches the job of a midwives group in a poor area of London at the end of the 1950's. At the same time the series promotes ruptures related to hegemonic representations about home and sewing, and aligns itself to contemporary and mystifying visions of maternity and of "being a mother".

Keywords: series; affects; women; feminism; intimacy. 


\section{Apresentação}

Tableau. Cinco mulheres sentadas na sala, luz difusa, acolhedora. Enfermeiras e freiras. Em primeiro plano, à esquerda, no braço do sofá, desfocados, retalhos quadrados, pequenos cortes de tecido, novelo de lã. Telefone toca. Elas interrompem o chá. As notícias não são boas. Estamos no oitavo episódio da segunda temporada ${ }^{2}$ do seriado britânico Call the midwife $e^{3}$ da emissora inglesa BBC. A série, baseada nas memórias da enfermeira Jennifer Worth (Call the midwife, Shadows of the workhouse e Farewell to the East End, sem traduções no Brasil), acompanha um grupo de parteiras em uma região pobre da Londres pós-Segunda Guerra, Poplar, no fim dos anos 1950, que trabalha em uma casa de partos, a Nonnatus House, comandada pela irmandade de São Nonato. A protagonista é Jenny, alter ego de Jennifer, enfermeira recém-chegada a Londres. Ao lado de Trixie, Cynthia e Chummy, ela trabalha como parteira com as irmãs Julienne, Bernadete, Evangelina e Monica Joan - freiras com formação de enfermagem. Na casa de parto, privilegiam-se nascimentos caseiros e partos normais; o médico só é chamado em caso de complicações. Os maridos não acompanham os nascimentos, e as enfermeiras monitoram a gestação, em espécie de pré-natal, assim como a infância das crianças e a saúde das mães na clínica paroquial do bairro. Até janeiro de 2017, foram cinco temporadas produzidas do seriado, em um total de 43 episódios, entre regulares e especiais, com média de 60 minutos cada. Em 25 de dezembro de 2016, um especial de Natal exibido no Reino Unido prenunciou a sexta temporada. As primeiras cinco temporadas estão disponíveis na Netflix, plataforma paga de distribuição de conteúdo audiovisual on-line . $^{4}$

No último episódio da segunda temporada (o $8^{\circ}$ ), o foco narrativo transforma uma das enfermeiras em mãe-personagem. Camilla, carinhosa e jocosamente chamada de Chummy ${ }^{5}$ (inclusive por ela mesma), teve complicações no parto do primeiro filho com o policial Peter. Por volta dos 39 minutos do episódio, começam a se desenrolar os eventos em foco neste trabalho. Houve descolamento de placenta e, em vez do parto caseiro, modus operandi rotineiro das parteiras, ela teve de ser levada ao hospital. Na sala da Nonnatus House, enquanto aguardam, as amigas e colegas de trabalho recebem a notícia de que houve outra hemorragia. Uma das enfermeiras, Cynthia, diz que a família

\footnotetext{
${ }^{2}$ Neste artigo seguimos a ordenação de temporadas e episódios da BBC.

3"Chamem a parteira”, em tradução livre.

${ }^{4}$ Até a conclusão deste trabalho, a série não foi exibida na TV a cabo ou aberta brasileiras.

${ }^{5}$ Chummy é de família aristocrática, mas desagrada e desaponta a mãe como projeto malsucedido de dama. O apelido, intimista e despojado, rejeitado pela mãe, é símbolo dessa persona.
} 
dela, na ilha de Madeira, precisa ser avisada. Jenny, sentada a seu lado no sofá, responde: "A família dela sabe, sim. A família dela está aqui nesta sala".

Ato contínuo, pega um retalho nas mãos. Vemos seguidos closes de mãos cosendo linha e retalho; diferentes cores de lã, diferentes mãos, agulhas perfurando tecido, rostos concentrados na tarefa. A câmera une as cenas como as mãos costuram os retalhos; a montagem audiovisual une as mãos que diegeticamente unem os retalhos, num labor coletivo e continuado. Tableau. Sete mulheres costuram, silêncio. Em off, a narradora (uma versão mais velha de Jenny, como rememorando) diz: "Era como se jamais tivéssemos sido tão próximas, jamais tão absortas numa única tarefa”.

Closes de mãos. Silêncio. Enquanto trabalhavam e rezavam, não havia necessidade de falar, Jenny relembra, em off. Surge a colcha, percorrida pela câmera, enorme, arrastando-se pelo chão, unindo o labor de todas, aproximando-as e as aproximando de Camilla. O tempo passou. Jenny e a irmã Julienne, a principal freira do convento, entram no quarto de hospital onde Chummy está, ainda desacordada. Na cadeira, o marido segura o recém-nascido. Lentamente, Jenny abre o pacote de papel pardo, preso com um pedaço da mesma lã que coseu a manta. As mulheres cobrem Chummy com a colcha, colocam o filho nos braços da mãe, que desperta. "Está tudo bem, estou aqui", diz ao bebê.

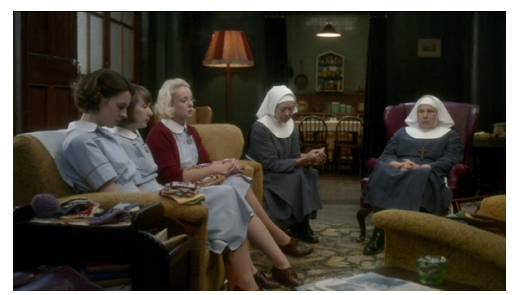

Figura 1: Parteiras à espera de notícias. Fonte: Call the midwife (2012-)

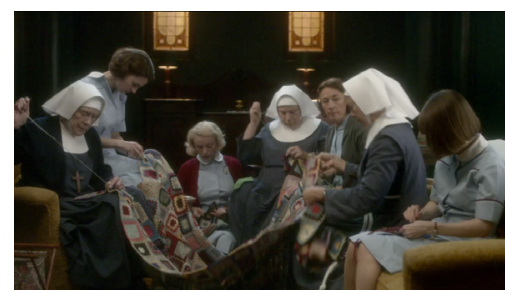

Figura 3: Labor coletivo.

Fonte: Call the midwife (2012-)

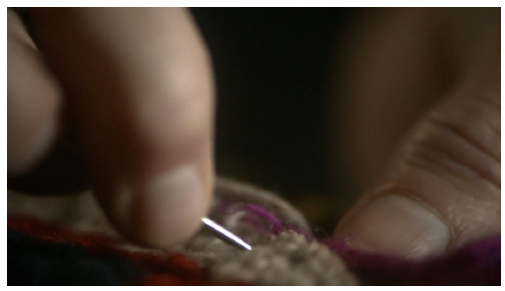

Figura 2: Close de mão cosendo. Fonte: Call the midwife (2012-)

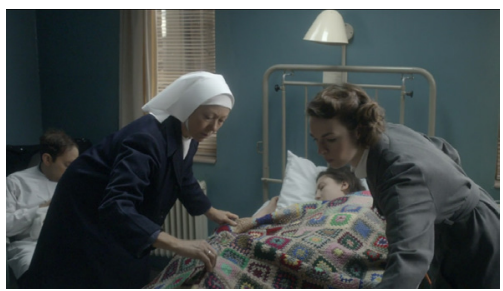

Figura 4: Parteiras cobrindo mulher. Fonte: Call the midwife (2012-) 
A sequência, de cerca de oito minutos, é montada intercalando as cenas das mulheres, em uma construção de intimidade, com planos médios do marido no corredor do hospital, chorando e aguardando a cirurgia da mulher. Mas não é Peter, um dos quatro personagens masculinos fixos de Call the midwife (com o médico, dr. Turner, o pároco Tom e o zelador do convento, Fred) que nos interessa, nem sua participação na sequência. Neste artigo, nos debruçamos sobre esses minutos de labor em torno da costura feminina para discutir afetos, silêncios, tempo, intimidade e subversão. A análise fílmica, que desconstrói o objeto em busca de reconstruí-lo (ou construir um novo objeto, teorizado, abstrato) a partir das perspectivas analíticas lançadas sobre ele, é nossa ferramenta. A análise fílmica nutre-se de conceitos, métodos e campos teóricos, uma vez que o movimento de imagens e sons gerando sentidos e significados dialoga com as artes, a literatura, a história, a filosofia, entre outros.

Aumont assim define a análise do filme: como "aplicação, desenvolvimento e invenção de teorias e disciplinas” (2004, p. 8), ou seja, apropriação de outros campos de acordo com o enfoque dado pelo pesquisador. Não há uma teoria unificada do cinema, mas diversas óticas para se aproximar do fenômeno; não há um método universal de análise do filme. Isso não significa que se deva abrir mão do rigor e da reflexão metodológica diante da singularidade das análises. Jullier e Marie também insistem nesse ponto: "não existe um código indecifrável, receita milagrosa ou método rígido" (2009, p. 15). O olhar do analista não cria um novo produto audiovisual, mas parte dele em busca de desvendar o que o produto oferece; o audiovisual é ponto de partida e chegada. Como método de análise, nos permite identificar recorrências, tensões, similitudes, mediações, diálogos possíveis e diferenças - para, aí então, realizarmos operações interpretativas que, no entanto, não se esgotam.

A sequência de Call the midwife que nos interessa, além de outras a que nos referimos, segue a forma do produto audiovisual como um todo: mise-en-scène clássica, construção narrativa clara e reiterativa, linguagem convencional e acessível. É um produto televisivo massivo de TV aberta (na Grã-Bretanha), ainda que seja produzido pela BBC, emissora britânica com produções mais refinadas em seu portfólio. Pode, inclusive, ser classificada como quality television ${ }^{6}$. É nesse contexto

\footnotetext{
${ }^{6}$ De acordo com Sarah Cardwell (2007), o conceito refere-se a certas características textuais que significam ou representam alta qualidade, como construção cuidadosa, boa atuação, boa captação e boa estória, entre outras. Ou seja, diz respeito ao nosso reconhecimento de certas características estéticas que a obra contenha, e está mais relacionado a uma descrição de gênero do que a uma avaliação crítica. Cardwell lembra ainda que os estudos sobre a quality television britânica diferem dos norte-americanos (onde o termo nasce), ao manterem não apenas uma distância crítica como emocional dos programas aos quais se dedicam analisar.
} 
produtivo que se desenvolvem as narrativas episódicas, em geral abordando uma ou duas gestações/nascimentos por episódio e as situações relacionadas ao caso - de característica procedimental -, paralelamente à exploração da vida de uma ou várias mulheres. Muitas vezes, o drama episódico opera como "lição de vida", iluminação para o aprendizado das protagonistas. Cada episódio pode ser compreendido como trama unitária, mas com o pano de fundo das subjetividades do elenco principal, que tecem a narrativa mais ampla ao longo das temporadas.

A Inglaterra que se descortina no seriado vive intensas transformações urbanas e sociais, que se mesclam às heranças do pós-guerra e ao início da paranoia nuclear. Nos episódios há famílias negras rejeitadas pela vizinhança, imigrantes indianos, ciganos, irlandeses que não são aceitos como inquilinos, velhos abandonados pela família. Abortos legais e ilegais, a talidomida como promessa contra enjoos, a expectativa pela chegada da pílula contraceptiva. As freiras enfrentam dilemas espirituais. Uma enfermeira vive uma relação proibida com uma colega de profissão, outra é alcoólatra. Parentes de personagens morreram em bombardeios, e muitos homens lutaram na guerra; alguns enfrentam crises do pânico advindas da síndrome do estresse pós-traumático. A Guerra Fria dá os primeiros sinais: moradores locais criam comitês de prevenção e abrigos antinucleares, e qualquer explosão é considerada atentado.

Apesar de buscar traçar esse panorama sócio-histórico, Call the midwife está ainda distante do que Silva (2015) define como drama seriado contemporâneo, que consegue esgarçar e aprofundar, complexificando o que é apresentado. Se fia sobretudo na construção clássica do drama televisivo, que permite uma codificação imediata do mundo representado e propõe, de certa maneira, uma "unidade totalizante e mítica” (p. 140) - ainda que as tramas não possam ser consideradas rasas. O seriado estaria, portanto, na fronteira entre produtos que oferecem apenas a experiência dramática da unidade episódica e os que complexificam as narrativas. Esse lugar fronteiriço se ressalta quando percebemos tanto o caráter conciliatório da narrativa quanto a imagem audiovisual seriada como potência afetiva; como modos de encontros, de relações entre mulheres; de afetos entre mulheres, enfim.

Em cada episódio, há mortes de mães e filhos, tentativas de abortos, filhos rejeitados pelos pais, depressão pós-parto, doenças sexualmente transmissíveis, adultérios. Tudo sob a ótica imutável das mulheres; são as mulheres e sua vida, seu trabalho, seus partos e seus filhos que estão em primeiro plano no seriado britânico. As personagens masculinas existem e, eventualmente, estão em foco, mas são marginalizadas em detrimento dos espaços monossexuais protagonizados pelas mulheres. No primeiro episódio da $2^{\text {a }}$ temporada, enquanto as enfermeiras assistem 
a um filme no cinema, a narradora deixa claros o protagonismo feminino e o papel dos homens na vida delas: "Nós servíamos as mulheres e vivíamos entre elas. Os homens eram criaturas com quem nos casávamos, com quem nos deslumbrávamos, ou a quem desejávamos e nos desconcertavam. Essencialmente, eles nos mantinham ocupadas, e eram só o que conhecíamos".

Nesse contexto, a complexa realidade inglesa é construída de maneira que as contradições são superadas, e os conflitos, resolvidos. Uma delas é a sequência da colcha, que apresenta ao espectador problema, conflito, drama e happy ending ${ }^{7}$; uma irrupção de felicidade, que se torna o núcleo afetivo da narrativa. Tal sequência, aliás, pode operar, em tal perspectiva, como alegoria de toda a produção. A moral das freiras e parteiras consegue harmonizar uma complexidade que, de resto, pouco se mostra afeita à conciliação, especialmente diante dos panoramas de diferença, exclusão e transformações que o seriado apresenta.

É impossível, portanto, dissociar esse imaginário conciliador daquilo que o seriado coloca em pauta: o parto e a maternidade, muitas vezes postos em cena como elementos capazes de apagar ou apaziguar os problemas dos casais, das famílias, das mães solteiras, das cidades, do país, e produzir promessas de felicidade, sendo direcionados, portanto, ao futuro - mesmo os bebês indesejados, os bebês natimortos ou com focomelia grave. Em um contexto contemporâneo de intensos debates e disputas de sentido acerca da maternidade, a produção e exibição do seriado ${ }^{8}$ constituem uma visão romantizada das possibilidades do parto e, especialmente, do “ser mãe", bem como do poder imbuído à geração e criação dos filhos perante o mundo. No segundo episódio da primeira temporada, a maternidade é chamada pela narradora de "presente" à mãe, deixando de lado os debates acerca do desejo de ser mãe. Ainda assim, o seriado problematiza diversas experiências de maternidade e as interliga a outras opressões de gênero e raça, classe e etnia - em menor grau.

\section{Domesticidade}

A ideia de lar emerge no bojo da ascensão da burguesia. Nele, se concentra a vida privada dos indivíduos; a criação dos filhos (ARIÈS, 1973), os cuidados com

\footnotetext{
${ }_{7}$ Morin conceitua esse final feliz como “a felicidade dos heróis simpáticos, adquirida de modo quase providencial, depois das provas que, normalmente, deveriam conduzir a um fracasso ou a uma saída trágica” (2011, p. 96). Para ele, o happy ending limita o universo da tragédia ao interior do imaginário contemporâneo.

${ }^{8} \mathrm{O}$ seriado teve em média 10 milhões de espectadores na Grã-Bretanha a cada temporada, ficando à frente de produtos consagrados, como o seriado de época Downton Abbey. Nos EUA, a exibição no canal educativo PBS foi responsável por cerca de $50 \%$ da audiência do canal naqueles períodos.
} 
a casa. Segundo Giddens, o lar, nesse contexto, se constrói como ambiente distinto do trabalho, sem o caráter instrumental daquele. É um lugar onde os integrantes da família nuclear, menor, com menos filhos, "podem esperar apoio emocional" (1993, p. 36), mas também são locais de "trocas (usualmente exploradoras) de serviço, trabalhar, dinheiro e sexo, assim como de coerção e violência" (FRASER, 2013 , p. 29). A família nuclear patriarcal duradoura é aquela em que, de acordo com Nancy Fraser, "maridos bem pagos, com empregos seguros, suportam esposas desempregadas ou com baixos salários" (2013, p. 8). Dentro dessa sociedade que institui e demarca papéis definidos para os gêneros - o de provedor e o de cuidadora, conforme a autora -, o lar é o espaço ao qual a mulher está restrita: no privado, no trabalho, na casa, na maternidade, na família. Subordinada ao lar, isolada do mundo exterior (GIDDENS, 1993), "trancada do lado de dentro" (WOOLF, 1985, p. 31), nesses espaços privados amizades entre mulheres ajudavam a diminuir as frustrações do casamento, mas também são compensadoras por si mesmas (WOOLF, 1985). A conquista dos espaços públicos pelas mulheres não garante a elas, contudo, o papel de provedoras, ou a ideia do papel de trabalhadoras, por conta da relação das mulheres com o trabalho pago no capitalismo patriarcal. Ainda que estejam no mercado de trabalho, as mulheres são "apresentadas diferentemente" dos homens, conforme Fraser, a partir da reflexão de Carole Pateman:

por exemplo, como trabalhadoras "de serviço" feminilizadas e às vezes sexualizadas (secretárias, trabalhadoras domésticas, vendedoras, prostitutas e aeromoças); como integrantes das "profissões de ajuda" que utilizam habilidades maternas (enfermeiras, assistentes sociais, cuidadoras infantis, professoras primárias); como alvos de assédio sexual; como trabalhadoras mal pagas, pouco especializadas, de baixo status em ocupações segregadas sexualmente; como trabalhadoras em tempo parcial; como trabalhadoras que fazem duploturno (ambos trabalho pago e doméstico, não remunerado); como "esposas trabalhadoras" e "mães trabalhadoras", por exemplo, primordialmente esposas e mães que secundariam e, eventualmente, "saem para trabalhar"; como "renda complementar". (2013, p. 35).

Trata-se, portanto, de uma diferença qualitativa do trabalho pago da mulher, e, portanto, de seu domínio sobre a esfera pública. Tanto em casa quanto no mercado de trabalho a divisão sexual do trabalho se manifesta, e as profissões das mulheres de Call the midwife, freiras e parteiras, estão profundamente relacionadas a isso. São cuidadoras em atividades de ajuda e conectadas à maternidade. A conquista do espaço público, então, é ambígua, subalterna. As mulheres do seriado saem de 
casa e percorrem Londres com a liberdade e independência dos homens; mas a elas foi legado o espaço profissional de qualidade secundária que cabe às mulheres.

Tendo acesso ou não ao mercado de trabalho, no lar a mulher trabalha. Labor doméstico, "da reprodução, não valorizado, não remunerado" (PERROT, 2007, p. 109). Esse trabalho doméstico tem sido, aponta Perrot, imprescindível para a sociedade, pois garante funcionamento e reprodução. Também é fundamental para a vida das mulheres, além de ser

um peso nos seus ombros, pois é responsabilidade delas. E um peso também na sua identidade: a dona-de-casa perfeita é o modelo sonhado da boa educação e torna-se um objeto de desejo para os homens e uma obsessão para as mulheres. $\mathrm{O}$ caráter doméstico marca todo o trabalho feminino: a mulher é sempre uma dona-de-casa. (PERROT, 2007, p. 114-115).

Décadas depois da efervescência dos movimentos feministas e das revoluções igualitárias, o laço duplo ainda permanece no que diz respeito ao trabalho doméstico. O compartilhamento das tarefas da casa entre homens e mulheres não ocorre; agora ocupantes da esfera pública, trabalhadoras, permanecem donas de casa no resto do tempo. Esse trabalho, classifica Perrot, “é invisível, fluido, elástico. E um trabalho físico, que depende do corpo, pouco qualificado e pouco mecanizado apesar das mudanças contemporâneas" (2007, p. 115).

Um desses trabalhos tem sido, e ainda é, a costura: "a costura, a manutenção das roupas, a cozinha, as conservas de frutas e carnes, a fabricação de veias nos levam ao centro da vida privada doméstica” (ARIÈS, 1973, p. 274). Para as mulheres das classes operárias, a costura historicamente ainda tinha outro papel - um meio de aumentar a renda familiar, enquanto, em casa, ela mesma fazia e consertava as roupas. Para as burguesas, esses trabalhos manuais, "tricô ou bordado, as 'pequenas coisas' do cotidiano as ocupam e as justificam” (PERROT, 2007, p. 117). Perrot afirma que, da mulher, diz-se que já nasce com agulha e linha nas mãos, quando, na verdade, aprende desde menina a atividade, aprendizagem paciente, pouco formalizado; saberes femininos transmitidos pela tradição e naturalizados como "essência" - e condenação, muitas vezes. Em casa, a costura efetiva-se como trabalho doméstico, mas também se manifesta, há séculos, como atividade profissional especializada das mulheres, conectada à importância do vestuário na sociedade ocidental; as modistas, as operárias da costura, da lavagem, dos tecidos, das roupas de cama, das lingeries, dos luxos têxteis dos mais ricos (PERROT, 2007). 
A costura como atividade doméstica feminina é um tema recorrente em Call the midwife, reforçando o pertencimento dessa atividade à esfera das mulheres, também e ainda no tempo diegético em que se passa a história. A irmã Monica Joan, uma das primeiras parteiras registradas do Reino Unido e fundadora da irmandade, está aposentada desde o início da trama, devido à idade e à senilidade. Velha e excêntrica, gosta de recitar John Keats e costuma receber tarefas menores para se ocupar e não atrapalhar o trabalho das outras. Entre essas atividades, a preferida é costurar, desde mantas e enxovais a animais de pelúcia, ou se rebelar por meio do exercício com tecidos (retalhado rendas para fazer pombas de tecido).

Em geral, a costura se exerce como comunhão entre as mulheres. No especial de Natal da segunda temporada, elas se reúnem à mesa para costurar, juntas, as roupas das crianças da peça natalina. Acolhem uma velha costureira da região, abandonada e senil, que Jenny ajuda ao descobrir o paradeiro dos cinco filhos dela (mortos), dos quais havia sido separada décadas antes ao enviuvar e, por isso, ser mandada para um hospício. Nessas sequências de costura, há felicidade e resgate; cenas iluminadas, cores vivas e risos. A trilha é uma canção natalina tradicional. Ainda que costurem, o exercício da feminilidade é subversivo: elas fazem fantasias porque querem; não há laço invisível de opressão prendendo-as à obrigação de consertar roupas de filhos ou maridos; não exercem os papéis de mães e esposas; não há renda complementar a ser obtida com esse trabalho. Ainda, criam um espaço de solidariedade para com outra mulher, por meio justamente da familiaridade com essa atividade "tão feminina”, a da costura. Costuram afetos.

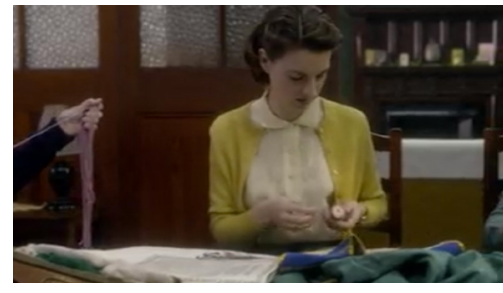

Figura 5: Jenny costurando. Fonte: Call the midwife (2012-)

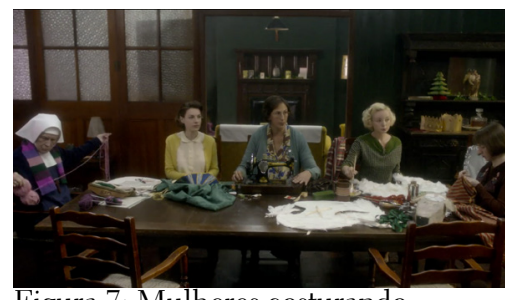

Figura 7: Mulheres costurando. Fonte: Call the midwife (2012-)

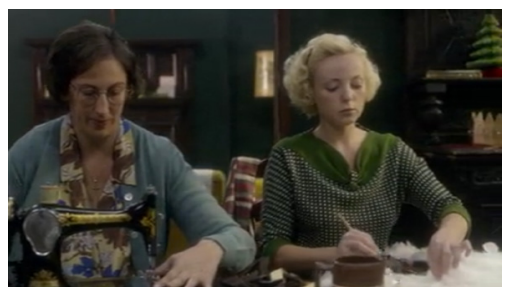

Figura 6: Chummy e Trixie preparando roupas. Fonte: Call the midwife (2012-)

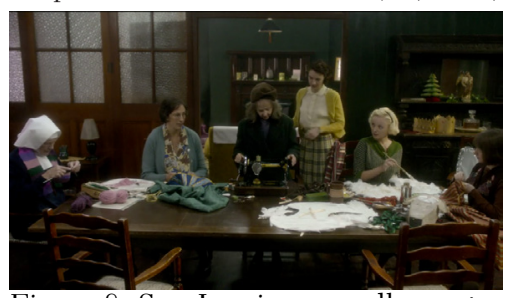

Figura 8: Sra. Jennings, a velha costureira, se reencontra com o labor. Fonte: Call the midwife (2012-) 
Neste e em outros momentos, a costura é agenciada pelas mulheres que desafiam a ordem patriarcal do lar, da mulher, e os sentidos tradicionais da costura, contudo em nenhum momento anterior à sequência descrita no início deste trabalho com tamanhas força e potência narrativas e visuais. Aquele momento, na sequência da confecção da colcha, condensa uma série de questões narrativas e visuais na série: primeiro, em relação à ideia de lar, que costumeiramente tende a desconsiderar as relações de poder e gênero que atravessam a concepção de casa. Historicamente, a casa não tem sido apenas abrigo em um mundo impiedoso, como sustenta a versão dominante, "mas cálculo instrumental e estratégico":

Ao mesmo tempo que libertam a mulher da ameaça da ausência de teto, e cumprem uma promessa, mantêm a linhagem de confinamento da mulher que sai de uma casa a outra, de um pai a um marido, sem experimentar a liberdade [...]. Dão conta, simultaneamente, de proteger a mulher mas enclausuram-na na espiral de atividades domésticas, de serviço, exploração. (GOMES BARBOSA, 2014, p. 209).

Para as mulheres do seriado, a casa não é espaço de opressão nem de confinamento. Se as mulheres de Call the midwife estão na sala, reunidas, não é porque estão confinadas àquele espaço de opressão e silenciamento: elas trabalham, andam e pedalam pela região mais pobre de Londres, dirigem, namoram (ainda que sob o recato do convento) e dançam. Transitam pelos espaços públicos com a mesma liberdade e autonomia com que exercem as tarefas domésticas. Têm agência, enfim. Sentam-se à sala por uma escolha ditada pelos afetos. Nesse sentido, casa, aqui, se aproxima de fato do que Giddens atesta ou do que Bachelard proclama, razão ou ilusão de estabilidade, corpo de imagens complexas de valores da intimidade, cantos de mundo, abrigos ou refúgios: "a casa abriga o devaneio, a casa protege o sonhador, a casa nos permite sonhar em paz” (BACHELARD, 2008, p. 201).

No convento, parteiras encontram abrigo diante da pobreza, à tristeza e às mazelas que encontram em seus labores diários. Nessa casa de mulheres, elas chegam ao espaço - e umas às outras - como conforto e abrigo. Não à toa Jenny demarca: elas são uma família. Família sem parentesco, formada por laços de afeto, em desafio ao modelo patriarcal. E, se o lar é o espaço da família, os sentidos produzidos pelo lar se efetivam na sala da casa em que essa família.

Outro espaço dessa família é a mesa da cozinha. Reiteradamente, o seriado nos apresenta mulheres sentadas a alguma refeição repassando o trabalho, se solidarizando. O alimento compartilhado na informalidade da mesa comunal é 
demarcação desse espaço monossexual, em que não há patriarca na cabeceira da mesa, em que a intimidade se dá entre amigas, colegas. A “mesa de jantar” da família nuclear patriarcal é subvertida pela mesa de jantar comunal.
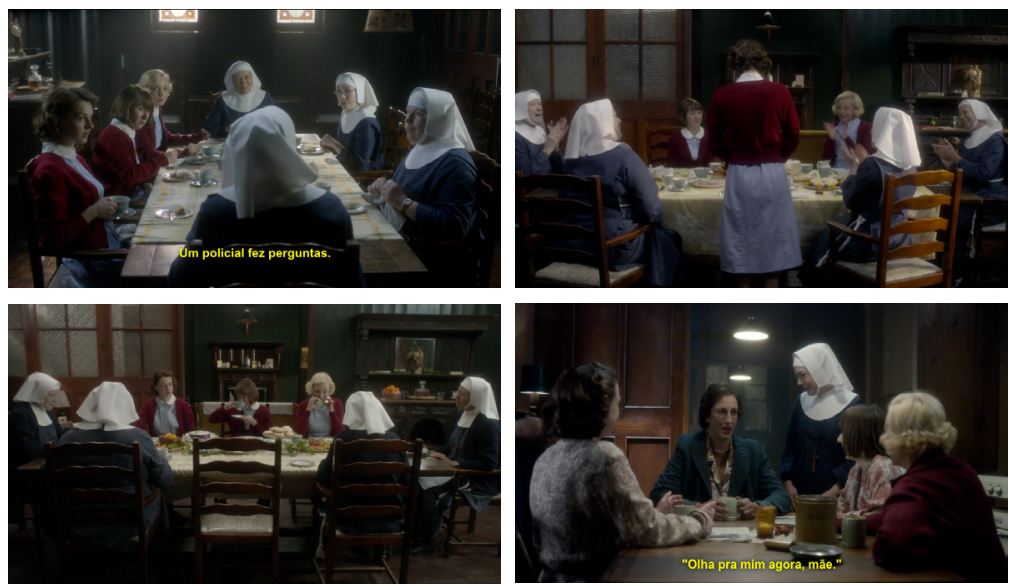

Figuras 9 a 12: Nas três primeiras temporadas, cenas da "família de amigas". Fonte: Call the midwife (2012-)

Além de subverter a acepção do lar como espaço de confinamento da mulher, ampliando seus sentidos, há assim outro sentido de família: no lugar da imagem burguesa nuclear de pai, mãe e filhos, há mulheres. Elas rejeitam esse modelo e, portanto, recusam certas ideias de feminilidade (mas, ao mesmo tempo, reforçam outras) que as conecta às imagens de esposas e mães.

Todas, freiras e enfermeiras, porém, estão dedicadas a trazer ao mundo justamente os filhos de diversos tipos de famílias - ou de nenhuma família. Filhos de mulheres, pois o nascimento é irremediavelmente produto da maternidade. $\mathrm{Na}$ sequência em destaque, percebemos que esses dois modelos de família, sangue e afeto, hegemônica e desafio, são conciliados e negociados por meio da confecção da colcha. Lopes resgata o termo utilizado pela fotógrafa Nan Goldin para descrever relações de afeto e proximidade que poderiam ser denominadas de família, mas são "famílias de amigos" (LOPES, 2016, p. 2); recriações familiares com desejo pela proximidade do modelo tradicional mas também por algo mais aberto, que se ancore em dependência mútua, amor, ternura9 (GOLDIN, 2007, p. 66). No seriado, é uma família de amigas.

\footnotetext{
${ }^{9}$ As fotografias de Goldin tratam de festas, encontros, enfim, modos de estar no mundo distintos daqueles do moralismo ingênuo de Call the midwife. Englobam períodos dos anos 1970 e 1980 em Nova York. Ainda assim, é possível expandir o conceito de "família de amigos" para relações de proximidade não sanguíneas baseadas em afetos.
} 
Chummy une a tradição burguesa patriarcal e a liberação feminina no pós-guerra: transita entre os dois universos, pois marido e filho a esperam no hospital, e sua família de afetos, as mulheres, oram por ela, cosem uma colcha, carregada de esperança. Na narrativa do seriado, a conciliação é utópica; quase não há crise ao longo das temporadas entre os papéis de Chummy como mãe, esposa ou parteira. Peter compreende as necessidades de plantões da mulher e divide os cuidados com a criança.

\section{Costura}

É na sala, no espaço da casa, que a colcha se materializa como objeto de afeto: objeto que, ao circular, acumula valor afetivo positivo (AHMED, 2010, p. $29)^{10}$. Compreendemos afeto como aquilo que mantém ou conserva a conexão entre ideias, valores e objetos, de acordo com Ahmed, e para nós, entre pessoas. Conforme Deleuze (2010), afetos (afectos) são devires não-humanos - entre humanos e objetos -, eternos tornar-se, fraturas na estabilidade; são também encontros e, nesse sentido, sempre possibilidades (pois devires) de relações. Afetos são encontros marcados pelo tempo - instantes. Durante aquela costura, circula um afeto entre os corpos, entre o objeto, entre aquelas mulheres, movimentando-se e contagiando-as, construindo um tempo dos afetos ${ }^{11}$.

A colcha feita pelas mulheres para outra mulher tem a capacidade de transmitir algo, investindo quem a recebe de afetos circulantes. Afetos saltam entre corpos: afeto comunicável pode inflamar nervos e músculos em conflagração a todos os tipos concebíveis de paixão (GIBBS apud AHMED, 2010). Para Ahmed, não se trata de um simples contágio entre corpos - o contágio das mulheres à colcha e da colcha à mulher - mas depende das contingências em que se é afetado. Na sequência em visionamento, o contexto de produção da colcha envolve um conjunto afetivo complexo: amizade, preocupação, tristeza, sofrimento; mas sobretudo esperança. $\mathrm{O}$ ato de coser adquire caráter quase místico, religioso: como reza, cada alinhavo é uma prece a Chummy, com expectativa de coisas boas (a melhora, a recuperação, o filho recém-nascido, o convívio). As mulheres, ali, não se reúnem em pranto de luto ou rendição, mas em luta silenciosa - como a reza com expectativa de vitória e repleta de esperança.

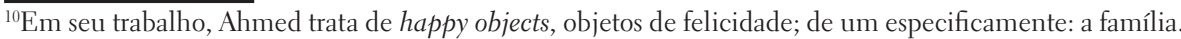

${ }^{11}$ Dada a natureza instável dos afetos, a nomeação destes é uma convenção útil.
} 
A reza é motivo recorrente em Call the midwife. As irmãs de São Nonnatus diariamente oram e cantam juntas. São sequências que se repetem, cada uma encapsulando uma trama importante, como provocando iluminação espiritual ou ajudando em alguma decisão das mulheres. Sempre à meia-luz, em codificação visual marcada, a câmera percorre a capela escura, os trajes também escuros das freiras e as velas acesas. Naqueles momentos de oração, transitam afetos: algumas parteiras buscam conforto na oração, outras buscam se encontrar. A ausência de alguma delas é sentida: está doente? Os sucessos e fracassos do labor do parto são expurgados e comunicados afetivamente durante essas sequências, que costuram relações afetivas entre as mulheres, em geral em direção ao passado ou ao presente. E, apesar de as freiras cantarem, é a impressão de silêncio que transparece. Conforto no silêncio voluntário. Tais sequências funcionam, muitas vezes, como catalisador dos desfechos dos episódios: os clímaces se desenrolam e as irmãs oram; o episódio se encaminha para o fim.
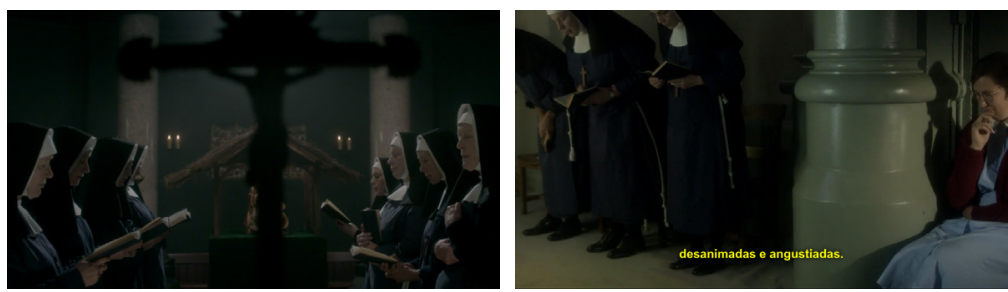

Figuras 13 e 14: Irmãs rezam enquanto conflitos se resolvem. Fonte: Call the midwife (2012-)

Na sequência da colcha, o ato de costurar é orientado ao futuro. A esperança é um afeto que aponta o futuro em algo; mira não o tempo presente, mas um porvir que há de ser melhor. É uma espera agente; a ação, aqui, é a costura. A costura das mulheres não é um ato individual, mas construção afetiva coletiva, em que cada fragmento compõe um objeto afetivo, compartilhado por todas e materializado num objeto físico que Chummy recebe; que a cobre e reconforta. Como elemento místico (e conciliador), logo após ser coberta e receber o filho nos braços, ela abre os olhos. Reza poderosa, nos diz a narrativa.

\section{Compartilhamento}

A colcha se constitui como objeto de esperança; como objeto afetivo dirigido ao futuro. Com a costura, configura-se também como ato de extrema intimidade entre 
aquelas mulheres, realizado na sala compartilhada, passada - ato e produto - de mão em mão, trecho de oração, conta de terço. Para Giddens, a intimidade é um "encontro de almas que tem caráter reparador" (1993, p. 56), preenchimento de vazios, tornar inteiros os indivíduos fragmentados. Intimidade, para o autor, tem a ver com disponibilidade, equilíbrio de abertura, vulnerabilidade e confiança (1993). Giddens refere-se a relacionamentos amorosos, mas a sequência de Call the midwife demonstra que outros laços afetivos, os laços dessa família de amigas, também efetivam intimidade. Intimidade entre mulheres, ligações femininas (female bondings). Essa intimidade compartilhada se relaciona às mudanças que o corpo e a mulher, postos em cena no audiovisual, vêm sofrendo nas últimas décadas, também devido ao impacto dos movimentos feministas e das teorias feministas do cinema e do audiovisual. Denilson Lopes diagnostica assim essa mudança:

Se as falas no mundo da ciência, do trabalho e da política eram hegemonicamente masculinas, os espaços da intimidade, da casa, do corpo deixam de ser apenas lugares de opressão e de uma fala única. Se o mundo exterior, das viagens, era dos homens, a intimidade deixa de prisão para emergir como possibilidade de resistência, de demarcação da diferença. (2006, p. 383).

Lopes (2006) ressalta que não se trata mais de grandes feitos, mas do cotidiano; de algo que emerge onde antes aparentemente "só havia silêncio e opressão". E o que há de mais cotidiano que um grupo de mulheres costurando em uma sala? O que as une naquele momento é também cotidiano: o nascimento de uma criança, a doença de uma mulher. Há uma intimidade específica e distinta entre elas, inacessível aos homens. Esse espaço é praticamente monossexual (LOPES, 2006) e evoca produtos audiovisuais como Colcha de retalhos (How to make an American quilt, Jocelyn Moorhouse, 1995), em que um grupo de amigas se reúne para costurar uma colcha de retalhos para o casamento de uma delas, enquanto lembram o passado. Conforme Lopes, no filme - como no seriado - a colcha aponta para a aposta; para o futuro. "Trata-se menos de nostalgia do que de uma recuperação de possibilidade de futuro" (2006, p. 390) $)^{12}$.

$\mathrm{O}$ ato da costura, de unir retalhos distintos por um liame similar, vidas diferentes unidas por algo, é justamente uma metáfora da potência desse universo de mulheres,

\footnotetext{
${ }^{12} \mathrm{O}$ quilt - a colcha de retalhos bordada coletivamente por mulheres com temas étnicos, folclóricos, culturais, religiosos - é uma forte tradição anglo-saxã que vem sendo analisada pelos estudos feministas e também apropriada pelas mulheres como ferramenta de empoderamento e crítica, ressignificando a imagem tradicional que conecta a costura à domesticidade. A feitura dos quilts tem se manifestado como transmissão cultural feminina.
} 
que pela proximidade, e pela potência desta pequena distância - "nunca estivemos tão próximas" - manifesta a intimidade sendo construída ali, na sala de estar. Não são apenas os retalhos que elas juntam na costura coletiva; são as próprias vidas sendo cosidas umas às outras, bordadas indelevelmente. Como na canção de Gilberto Gil:

É a sua vida que eu quero bordar na minha/Como se eu fosse o pano e você fosse a linha/E a agulha do real nas mãos da fantasia/Fosse bordando ponto a ponto nosso dia a dia/E fosse aparecendo aos poucos nosso amor/Os nossos sentimentos loucos, nosso amor/O zig-zag do tormento, as cores da alegria/A curva generosa da compreensão/Formando a pétala da rosa, da paixão/A sua vida o meu caminho, nosso amor/Nocê a linha e eu o linho, nosso amor/Nossa colcha de cama, nossa toalha de mesa/Reproduzidos no bordado/A casa, a estrada, a correnteza/O Sol, a ave, a árvore, o ninho da beleza. (GIL, 1983).

Gil fala de amor-paixão, na tipologia amorosa de Costa (1998). Evocamos o cáritas, a mística do amor-amizade cristão, segundo Costa ${ }^{13}$. Ou, nas palavras da narradora, no $5^{\circ}$ episódio da primeira temporada: "Não existem versões de amor. Existe apenas amor". Na sequência de Call the midwife a que nos dedicamos, cada mulher é o pano, o retalho, e a rede de afetos que traçam por meio da colcha é a linha que as conecta, criando um compartilhamento de vidas, de sonhos, de amizade e de esperança. E mais: os fatos de serem mulheres solteiras no pós-guerra; mulheres solteiras e trabalhadoras no pós-guerra; mulheres solteiras trabalhadoras na área mais pobre da Inglaterra no pós-guerra. O trabalho que realizam também integra esse fio: são parteiras e ajudam mulheres a parirem em casa.

A intimidade criada pelo morar compartilhado, pelo labor e pelas identidades construídas sobre o parto e a maternidade é elevada à potência máxima na sequência de costura da colcha. Conflitos, ressentimentos e diferenças são apaziguados em nome de uma comunicação com a outra, com as outras subjetividades. Trata-se de uma comunicação sem linguagem: elas optam por ficar em silêncio, e nem há necessidade de nada dizer. Ao admitirmos que a mulher atua em território masculino, já que a linguagem é patriarcal (NYE, 1995), o uso da costura como interligação de subjetividades representa de um lado a fuga da estruturação sexista e desigual da linguagem, das palavras, e, de outro, propõe fazer tal operação por meio da subversão de uma atividade delegada - compulsoriamente - à mulher para controle, submissão e cumprimento de tarefas invisíveis.

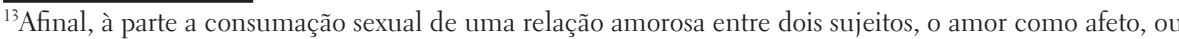
como "crença emocional” (COSTA, 1998, p. 12), tem semelhanças entre a versão passional e a versão amiga.
} 
No lugar de prender a mulher à casa, ao lar opressor, a costura é ativa, voluntária e orientada para o futuro. Está imbuída de afetos positivos e é exercida justamente em uma casa à qual a mulher não está presa, mas onde encontra liberdade (em termos). É uma costura de Aracne, que ousou desafiar Atena e mostrou, em sua tapeçaria, não a glória grega, mas "a brutalidade e trapaças dos homens e as súplicas lamentosas das mulheres, arrastadas para longe dos filhos, da família, da pátria” (NYE, 1995, p. 9). Ao contrário de Aracne, as parteiras e freiras não são punidas, sem nada de melhor esperar para o futuro. Renascidas, como aranhas subversivas, tecem as próprias vidas, os caminhos pelos quais constroem as intimidades compartilhadas e os afetos que circulam entre elas.

A encenação audiovisual do ato da costura é feita, como dito, em forma de costura, retalhos - trabalho lento, de ritmo compassado. A partir do ponto de vista objetivo, da instância narradora (e não da personagem-narradora, que se lembra) que vê a intimidade compartilhada em plano geral, em montagem paralela as várias parteiras, em close ou primeiros planos, costuram; closes das mãos perfurando os retalhos; travelling da câmera percorrendo a colcha que é criada. À medida que a colcha se materializa, os planos se aproximam, até chegar a primeiros planos, closes e detalhes (em alternância recorrente com o tableau das mulheres). A materialização da colcha é acompanhada de construção de intimidade e troca de esperança; os planos tornam-se mais íntimos. A elipse temporal em meia-luz. Em oposição ao espaço compartilhado e à esperança conjunta daquelas mulheres, Peter, o marido, aparece em planos médios laterais no corredor do hospital, sozinho. Quando Chummy sai da cirurgia, Peter fica a seu lado; mas ela só acorda quando as mulheres depõem sobre ela o manto e lhe deitam o filho no colo. O que nos informa tal decupagem é que a potência reside nas trocas afetivas de esperança feminina, não no sofrimento do marido; que o poder está na maternidade, no filho que é deitado ao lado da mãe, e ela desperta para ele; nas mãos de mulheres que transmitem saberes, que utilizam aprendizados para o que desejam, não para o que desejam outros ou para o que o lar necessita.

\section{Desenlace}

A sequência em análise coloca em evidência a maternidade pela perspectiva do poder que confere às mulheres: como parteiras, as protagonistas têm capacidade de agência e transformação de si e dos mundos ao redor. Com e/ou pelos filhos, as mães agenciam as próprias vidas, os companheiros, a pobreza e as adversidades. 
Em Call the midwife, é-nos apresentado um passado nostálgico e conciliatório que, no entanto, evoca de maneira aguda um dos tópicos mais efervescentes das discussões feministas contemporâneas: a maternidade. Devido a tal proposição, a série propõe um imaginário de maternidade não isento de tensões, mas capaz de transpô-las pela própria força.

A sequência sobre a qual nos debruçamos surge como núcleo narrativo, especialmente nas três primeiras temporadas: condensa, naqueles minutos, a gama de temáticas e enunciações apresentada até ali e no futuro, que ressoam também em sequências de oração e refeições. Tem imensas potências imagética e narrativa, e é por meio dessa potência que explora a esperança como afeto circulante por meio de um objeto, a colcha, costurado entre mulheres. A esperança é um afeto, aqui, direcionado ao futuro: trabalha com outro tempo que não aquele em que se efetiva, mas a expectativa de uma mudança no porvir.

$\mathrm{O}$ ato da costura, por meio do qual as mulheres fazem circular afeto e com a qual constroem uma intimidade compartilhada, é subversivo em relação aos modos pelos quais a costura das mulheres foi vista na história. Por séculos, coser integrou o rol de feminilidades compulsórias ensinadas às meninas e naturalizadas como características femininas, obrigações que elas deveriam cumprir em casa. Na sequência do seriado, a costura não atende a nenhuma necessidade de serviço doméstico; surge como desejo, ato de liberdade e compartilhamento. Para deixar claro o protagonismo dos afetos, da intimidade e da esperança na sequência, a montagem opera para opor a solidão masculina à cumplicidade - e ao poder - feminino.

Call the midwife traz o protagonismo feminino à toa não apenas nas personagens, mas nas temáticas, na construção visual e nos afetos que evoca: tratam-se de modos de as mulheres estarem no mundo, se relacionarem; tratamse, enfim, de afetos entre mulheres, amor, amizade, solidariedade e, sobretudo, intimidade. A produção do seriado também reflete esse protagonismo feminino: dos atuais 43 episódios produzidos, 30 são comandados por diretoras, e apenas 6 foram escritos por homens (um deles em coautoria). Estamos no território selvagem da autoria feminina, da autoridade da experiência (SHOWALTER, 1994), em que a mulher é seu próprio assunto, navegando em uma zona inacessível à hegemonia androcêntrica, nas tradições das mulheres, por meio da "natureza sutil e elusiva" da prática de produção feminina (SHOWALTER, 1994, p. 31). É uma ficção televisiva que carrega os pesos cumulativos da experiência e da exclusão, diz a autora. A zona selvagem, território feminino, é, de acordo com Showalter, uma grande fronteira, mas que não oprime ou confina: é acesso para o mar. 


\section{Referências}

AHMED, S. "Happy objects". In: GREGG, M.; SEIGWORTH, G. J. (Org.). The affect theory reader. Durham: Duke University Press, 2010. p. 2951.

ARIÈS, P. História social da criança e da família. 2. ed. Rio de Janeiro: Guanabara, 1973.

AUMONT, J.A análise do filme. Tradução Marcelo Félix. Lisboa: Texto \& Grafia, 2004.

AUMONT, J. et al. A estética do filme. Campinas: Papirus, 2012.

BACHELARD, G. A poética do espaço. Tradução Antonio de Pádua Danesi. 2. ed. São Paulo: Martins Fontes, 2008.

CARDWELL, S. "Is quality television any good? Generic distinctions, evaluations and the troubling matter of critical judgement". In: MCCABE, J.; AKASS, K. (Org.). Quality TV: contemporary American television and beyond. New York: I.B. Tauris, 2007, p. 19-34

COSTA, Jurandir Freire. Sem fraude nem favor - estudos sobre o amor romântico. Rio de Janeiro: Rocco, 1998.

DELEUZE, G.; GUATTARI, F. O que é a filosofia? Tradução Bento Prado Jr. e Alberto Alnso Muñoz. 3. ed. São Paulo: Editora 34, 2010.

FRASER, N. Fortunes of feminism: from state-managed capitalism to neoliberal crisis. London/Brooklin: Verso, 2013.

GIDDENS, A. A transformação da intimidade: sexualidade, amor e erotismo nas sociedades modernas. Tradução Magda Lopes. São Paulo: Unesp, 1993.

GIL, G. “A linha e o linho”. In: Extra. Nova York: WEA Discos, 1983.

GOLDIN, N. "Introduction”. In: CAMPANY, D (Org.) The cinematic. Documents of contemporary art. London/Cambridge: Whitechapel/The MIT Press, 2007, p. 66.

GOMES BARBOSA, K. Encantamentos de corpo e alma: representações do amor de Jane Austen no audiovisual. 2014. 344 f. Tese (Doutorado) - Curso de Comunicação Social, Programa de Pós-graduação da Faculdade de Comunicação, Universidade de Brasília, Brasília, 2014.

JULLIER, L.; MARIE, M. Lendo as imagens do cinema. Tradução Magda Lopes. São Paulo: Senac, 2009.

LOPES, D. "Cinema e gênero". In: MASCARELLO, F. (Org.). História do cinema mundial. Campinas: Papirus, 2006. p. 379-394.

La historia como fiesta y encuentro. 2016. No prelo.

MORIN, E. Cultura de massas no século XX: o espírito do tempo, I: neurose. 10. ed. Rio de Janeiro: Forense Universitária, 2011. 
NYE, A. Teoria feminista e as filosofias do homem. Rio de Janeiro: Rosa dos tempos, 1995.

PERROT, M. Minha história das mulheres. São Paulo: Contexto, 2007.

SHOWALTER, E. "A crítica feminista no território selvagem". In: HOLANDA, H. B. (Org.). Tendências e impasses: o feminismo como crítica da cultura. Rio de Janeiro: Rocco, 1994, p. 23-57

SILVA, M. V. B. "Origem do drama seriado contemporâneo". Matrizes, São Paulo, v. 9 , n. 1, p. 127-143, 2015.

WOOLF, Virginia. Um teto todo seu. Tradução Vera Ribeiro. Rio de Janeiro: Nova Fronteira, 1985.

\section{Referências audiovisuais}

CALL the midwife. Criação: Heidi Thomas. Great Britain: BBC, 2012-. Série. 44 episódios.

HOW to make an American quilt. Criação: Jocelyn Moorhouse. USA, 1995. 